\title{
A New Process of Thermoplastic Polypropylene Reinforced by Interlayered Activated Carbon Fiber Treated by Electron Beam Irradiation under Nitrogen Gas Atmosphere with Oxygen Prior to Assembly and Hot-Press
}

\author{
Shodai Kitagawa ${ }^{1, *}$, Hideki Kimura ${ }^{1,2}$, Helmut T. Uchida ${ }^{1}$, Michael C. Faudree ${ }^{1,2,3}$, \\ Akira Tonegawa $^{2}$, Satoru Kaneko ${ }^{4}$, Michelle Salvia ${ }^{5}$ and Yoshitake Nishi ${ }^{1,2,3,4,5}$ \\ ${ }^{1}$ Graduate School of Engineering, Tokai University, Hiratsuka 259-1292, Japan \\ ${ }^{2}$ Graduate School of Science \& Technology, Tokai University, Hiratsuka 259-1292, Japan \\ ${ }^{3}$ Tokyo City University, Faculty of Liberal Arts and Science, Yokohama 224-8551, Japan \\ ${ }^{4}$ Kanagawa Institute of Industrial Science and Technology, Ebina 243-0435, Japan \\ ${ }^{5}$ Ecole Centrale de Lyon, Ecully Cedex 69134, France
}

A new process of internal activation of carbon fiber reinforced thermoplastic polymer (CFRTP) of polypropylene (PP) by applying electron beam irradiation $(\mathrm{EBI})$ under oxygen $\left(\mathrm{O}_{2}\right)$-rich nitrogen gas $\left(\mathrm{N}_{2}\right)$ atmosphere to $\mathrm{CF}$ chopped strand matt (CSM) layers prior to assembly and hot press to strengthen the typically weak $\mathrm{CF}$ /thermoplastic polymers (TPs) adhesion was proposed. Samples were interlayered composite with layup of alternating PP and $\mathrm{CF}$ plies, $[\mathrm{PP}]_{4}[\mathrm{CF}]_{3}$. Composite fabrication was performed by one directional hot-press under constant pressure of 4.0 MPa at $473 \mathrm{~K}$ for $1 \mathrm{~min}$. Results showed applying an optimum $0.22 \mathrm{MGy}$-EBI under protective $\mathrm{N}_{2}$ gas with $\mathrm{O}_{2}$ concentrations between $200 \mathrm{ppm}$ and $200,000 \mathrm{ppm}$ mostly improved the bending strength $\left(\sigma_{\mathrm{b}}\right)$ while reducing strain at the bending strength $\left(\sigma_{\mathrm{b}}\right)$ apparently increasing the elasticity. The method appears to work well for the weakest samples in the data sets: at low accumulative probability $P_{\mathrm{f}}=0.06$ by median rank method, $\sigma_{\mathrm{b}}$ was apparently improved by the $200 \mathrm{ppm}$ and $2,000 \mathrm{ppm} \mathrm{O}_{2}$ atmospheres. Namely, $0.22 \mathrm{MGy}-\mathrm{EBI}$ under $\mathrm{N}_{2}$ gas atmosphere with $200 \mathrm{ppm}$ to $2,000 \mathrm{ppm}-\mathrm{O}_{2}$ improved $\sigma_{\mathrm{b}}$ at $P_{\mathrm{f}}=0.06(57 \mathrm{MPa}$ ) about $21 \%$, over that of untreated (47 MPa). Strength increase could be explained by mutual entangling of both sizing epoxy film on $\mathrm{CF}$ and $\mathrm{PP}$ with strong covalent bonding, which formation of direct $\mathrm{CF}: \mathrm{C}: \mathrm{C}$ :PP induced by EBI and oxygen assisted $\mathrm{CF}: \mathrm{C}: \mathrm{O}: \mathrm{C}: \mathrm{PP}$ by concentrating the $\mathrm{O}_{2}$ gas molecules from $200 \mathrm{ppm}$ to $2,000 \mathrm{ppm}-\mathrm{O}_{2}$ in $\mathrm{N}_{2}$ atmosphere, rather than weak molecular bonding $\mathrm{CF}-\left(\mathrm{H}_{2} \mathrm{O}, \mathrm{N}_{2}, \mathrm{O}_{2}\right)$-PP for the untreated samples. Moreover, the action of the EBI apparently acts to clean residual $\mathrm{H}_{2} \mathrm{O}$, $\mathrm{N}_{2}$, and $\mathrm{O}_{2}$ to purify and activate the $\mathrm{CF}$ surface increasing polar group and active site density. They most likely contributed to bending strength enhancement. The $0.22 \mathrm{MGy}$-EBI in $\mathrm{O}_{2}$-rich $\mathrm{N}_{2}$ atmosphere appears to be a viable method to increase carbon fiber-thermoplastic polypropylene adhesion enhancing reliability and safety of the PP-CFRTP. [doi:10.2320/matertrans.M2018335]

(Received October 26, 2018; Accepted January 10, 2019; Published February 18, 2019)

Keywords: carbon fiber, electron beam irradiation, thermoplastic, polypropylene, interface, bending strength, hot-press

\section{Introduction}

Climate change has been a serious problem for our earth. Therefore, lighter and stronger materials contributing to lowering vehicle $\mathrm{CO}_{2}$ emissions are essential. There is vital need for technical innovations such as lighter weight cars and development of electric vehicles (EVs) and solar vehicles (SVs) along with electric powered airplanes proposed by JAXA. Demand for carbon fiber reinforced polymers (CFRPs) has been expected to increase to replace hightension steel components along with use for moldable EVs car bodies.

It follows thermoset polymers, widely used for CFRP such as epoxy have higher ultimate strength than thermoplastics (TPs). However, disadvantage is requiring long solidification times and cannot be recycled making mass-waste disposal a serious problem.

On the other hand, thermoplastic polypropylene (PP) is widely used as an eco-friendly commercial polymer that can be recycled and reformed, has shorter solidification cycle times, decent strength, and lower cost. Solidification time for PP is only about $10 \%$ that of epoxy reducing energy consumption. Other advantages of PP are heat resistance and high chemical resistance: while thermoplastics in general have higher crack resistance than thermosets. PP belongs

*Graduate Student, Tokai University to the polyolefin group being partially crystalline and nonpolar.

However, the typically weak bonding between $\mathrm{CF}$ and TP pose serious challenges since $\mathrm{CF}$ lattice structure has graphitic basal planes with non-polar surface and is reported $^{1-3)}$ to be chemically inert due to manufacturing step of high temperature carbonization and graphitization. ${ }^{4)}$ Moreover, surface smoothness, negligible adsorption characteristics, and lipophobicity lead to insufficient bonding with matrix materials. ${ }^{5,6)} \mathrm{CF}$ has drawback of poor adhesion with $\mathrm{PP}$ resulting in lower mechanical properties from easy fiber pull-out due to low contact area at non-polar CF/PP interface.

Therefore, increasing adhesion of $\mathrm{CF}$ to matrix material has been a major goal in composite design. The literature reports several CF surface treatment methods. ${ }^{1,2,7-20)}$ Acidic modification creates a rougher surface possibly creating higher friction at the interface. ${ }^{7)}$ However, it can cause surface damage and weight loss ${ }^{9)}$ decreasing strength. ${ }^{2,8)}$ Widely researched is plasma CF surface modifications ${ }^{10-12)}$ reported to be successful in increasing interlaminar shear strength of CFRP. Plasma oxidation of CF was found to increase interfacial shear stress of CFRP epoxy composites from $6 \mathrm{MPa}$ to $42 \mathrm{MPa} .{ }^{13)}$

Many methods to increase adhesion create polar functional groups on the CF surface. ${ }^{14-16)}$ Electro-polymer coating has been carried out depositing polymer coatings on CF surface by chemical grafting reactions introducing functional groups 
$-\mathrm{OH},-\mathrm{NH}_{2}$, and $-\mathrm{COOH}$ to increase $\mathrm{CF}$ adhesion to epoxy, and the strength of $\mathrm{CF}$ itself. ${ }^{14)}$ Rare earth particle attachment method increases functional polar groups on CF surface has improved mechanical properties. ${ }^{15,16)}$

Applying high energy irradiation to $\mathrm{CF}$ for example ions and $\gamma$-rays have been found to enhance fiber/matrix adhesion without use of catalyst. ${ }^{17,18)}$ The high energy creates active sites in the crystal lattice while increasing surface roughness. High energy Ar+ ion irradiation $(0.6 \mathrm{keV}$ to $1.4 \mathrm{keV})$ showed carbonyl peak and broadened-OH peak of FTIR (Fouriertransformation infrared spectroscopy) increasing polarity and H-bond formation at CF interface. ${ }^{19)}$ A $0.30 \mathrm{MGy}$ dose of Co60 $\gamma$-ray irradiation has been reported to increase surface roughness of $\mathrm{CF}^{20)}$

However, recently surface activation by applying a light electron $\left(\mathrm{e}^{-}\right)$charge by electron beam irradiation (EBI) to $\mathrm{CF}$ surface to increase adhesion with polymer matrix has had success. EBI is a relatively easy method that does not use atoms or any catalyst. Moreover, EBI does not require chemical treatment of the CF. Large areas, such as LED TV screens can be treated.

When EBI activates the CF surface, it decreases dangling bond density in the hexagonal graphite structure as evidenced by a decrease in electron spin resonance (ESR) peak intensity. ${ }^{21)} \mathrm{CF}$ has been reported to naturally contain dangling bonds in its hexagonal structure. ${ }^{21)}$ The EBI has been reported to enhance crack resistance and increase tensile fracture stress and elasticity, increasing ductility strengthening the $\mathrm{CF}$ itself. ${ }^{22)}$

Moreover, EBI activated CF has been reported to increase adhesion to thermoplastics increasing tensile properties in [Ti/EBCF/ABS] joints 2.1 times higher than untreated [Ti/ $\mathrm{CF} / \mathrm{ABS}] ;{ }^{23)}$ and $[\mathrm{Ti} / \mathrm{EBCF} / \mathrm{PC}]$ joints 3.0 times higher than untreated $[\mathrm{Ti} / \mathrm{CF} / \mathrm{PC}] .{ }^{1)}$ Increased charge site distribution at the $\mathrm{CF}$ surface is homogeneous since $\mathrm{CF}$ is a strong conductor of electricity. The increased charge at the $\mathrm{CF}$ surface contributes to bonding of CF with TPs. Since EBI appears to enhance the nucleation sites and then increases the friction force at $\mathrm{CF} / \mathrm{TP}$ polymer interface, it prevents CF pull-out prior to dipping into thermoplastic ABS or PC, resulting in improving tensile strength.

Illustrated in Fig. 1 is schematic drawing of $\mathrm{PP} / \mathrm{CF}$ interface for CFRP. Figure 1(a) shows the interface with air molecules from the atmosphere $\left(\mathrm{O}_{2}, \mathrm{H}_{2} \mathrm{O}_{(\mathrm{g})}\right.$, and $\left.\mathrm{N}_{2}\right)$ that are assumed to act to create weak Van Der Walls attractive forces for PP reinforced carbon fiber untreated. This results in typical low friction with low point contact density.

Up to now, EBI in typical $\mathrm{N}_{2}$ atmosphere has been used to create stronger adhesion of $\mathrm{CF}$ to $\mathrm{TPs}^{1,23)}$ with EBI acting to clean the $\mathrm{CF}$ surfaces while activating CFs increasing intermolecular bonding with $\mathrm{CF}$ hexagonal structure $\pi$ electrons. However, to increase adhesion further, we employ the novel process of coupling the EBI activation with creating polar groups on the $\mathrm{CF}$ surface to proliferate covalent bonds as shown in Fig. 1(b). Since we found 0.22 MGy to be the optimum EBI dose for the $[\mathrm{PP}]_{4}[\mathrm{CF}]_{3}$ composite samples, we applied it in $\mathrm{O}_{2}$-rich $\mathrm{N}_{2}$ atmosphere for increased interfacial bonding and bending properties.

The purpose of the present study is to improve adhesion of carbon fiber to thermoplastic polypropylene by using a new
(a)Untreated Intermolecular weak bonding

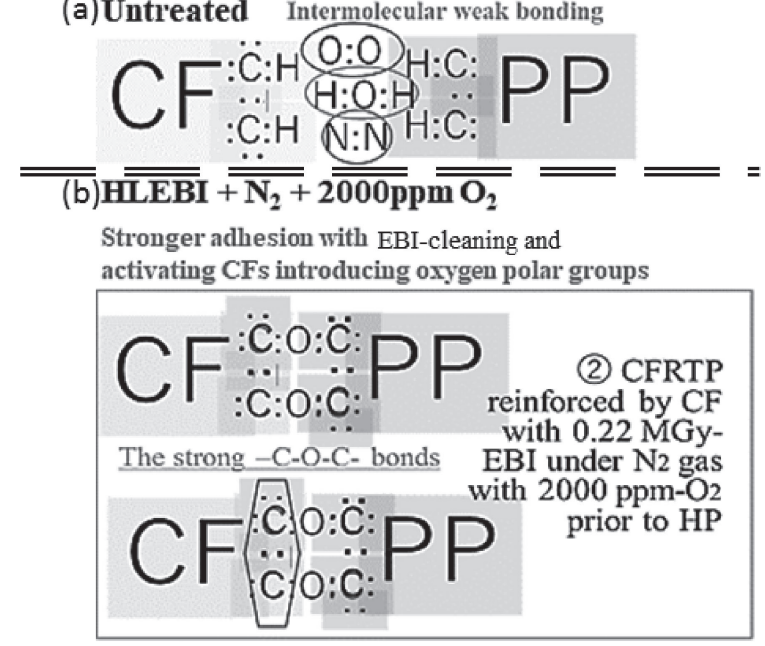

Fig. 1 Schematic diagram of CF/PP interface untreated (a), and EBItreated in $\mathrm{O}_{2}$-rich $\mathrm{N}_{2}$ atmosphere creating stronger covalent bonds (b).

process of applying EBI under oxygen $\left(\mathrm{O}_{2}\right)$-rich nitrogen gas $\left(\mathrm{N}_{2}\right)$ atmosphere to interlayered carbon fiber chopped strand matts (CF-CSMs).

\section{Experimental Procedure}

\subsection{Composite fabrication}

The 55 vol\%-carbon fiber reinforced thermoplastic polypropylene (PP-CFRTP) samples were constructed with 3 layers of carbon fiber $\left(300 \mathrm{~g} / \mathrm{mm}^{3}\right.$-Chopped strand matt (CSM), TR3110M, Mitsubishi Rayon Ltd. Tokyo) alternating between 4 layers of thermoplastic polymer sheet (Polypropylene; BC06C Novatec, Nissho Ltd. Tokyo). ${ }^{24)}$ EBI (see next section) was performed on both sides of each CF-CSM prior to assembly into the [PP-CF-PP-CF-PP-CF-PP] layup represented here as $[\mathrm{PP}]_{4}[\mathrm{CF}]_{3}$.

After assembly, solidification was performed by one directional hot-press (IMC-185A, Imoto Machinery Co., Ltd.) under 4.0 MPa at $473 \mathrm{~K}$ for $1 \mathrm{~min}$. Sample dimensions: length, width and thickness were $80 \mathrm{~mm} \times 10 \mathrm{~mm} \times 2 \mathrm{~mm}$, respectively.

\subsection{Condition of EBI}

The CSMs were homogeneously irradiated by an electroncurtain processor (Type CB175/15/180L, Energy Science Inc., Woburn, MA, Iwasaki Electric Group Co., Ltd., Tokyo) prior to assembly with PP and hot press. ${ }^{25-34)}$ The CFs were homogeneously irradiated by the linear electron beam gun with low energy through a titanium thin film window attached to a $240 \mathrm{~mm}$ diameter vacuum chamber. A tungsten filament in a vacuum was used to generate the electron beam at a low energy condition, where acceleration potential $\left(V_{\text {Acc }}\right.$ : $\mathrm{keV}$ ) of $170 \mathrm{keV}$ and the irradiating current density (I) of $0.089 \mathrm{~A} \times \mathrm{m}^{-2}$.

Although the electron beam is generated in a vacuum, the irradiated samples are kept under protective nitrogen at atmospheric pressure. The distance between the sample position and the window was $25 \mathrm{~mm}$. To prevent oxidation, the samples were kept in the protective atmosphere of nitrogen gas with a residual concentration of oxygen below 
$300 \mathrm{ppm}$. The constant flow rate of nitrogen gas was set to be $1.5 \mathrm{~L} / \mathrm{s}$ at $0.1 \mathrm{MPa}$ nitrogen gas pressure. Each irradiation dose (0.0432 MGy) was applied for only a short time $(0.23 \mathrm{~s})$ to avoid excessive heating of the sample; the temperature of the sample surface remained below $323 \mathrm{~K}$ just after irradiation. The sample in the aluminum plate holder $(0.15 \mathrm{~m} \times 0.15 \mathrm{~m})$ was transported on a conveyor at a constant speed of $10 \mathrm{~m} / \mathrm{min}$. The sheet EBI was applied intermittently; one sweep going one way is $0.0432 \mathrm{MGy}$. Repeated irradiations to both side surfaces of the samples were used to increase the total irradiation dose. The interval condition of $30 \mathrm{~s}$ was applied between each sweep. The irradiated dosage was proportional to the irradiation current $(I, \mathrm{~mA})$ and number of irradiations $(N)$, whereas it was inversely proportional to the conveyor speed $(S, \mathrm{~m} / \mathrm{min})$.

The irradiation dose was controlled by the integrated irradiation time for each of the samples. Here, irradiation dose was corrected by using an FWT nylon dosimeter of RCD radiometer film (FWT-60-00: Far West Technology, Inc. 330-D South Kellogg Goleta, California 93117, USA) with an irradiation reader (FWT-92D: Far West Technology, Inc. 330-D South Kellogg Goleta, California 93117, USA). The dose was $0.0432 \mathrm{MGy}$ at each irradiation. Based on the mean density $\left(\rho: \mathrm{kg} \times \mathrm{m}^{-3}\right)$ and irradiation potential at the specimen surface $(\mathrm{V}: \mathrm{keV})$, the penetration depth $\left(D_{\mathrm{th}}: \mathrm{m}\right)$ of EBI is expressed by the following equation. ${ }^{35)}$

$$
D_{\text {th }}=66.7 \mathrm{~V}^{5 / 3} / \rho
$$

Using the principal form of eq. (1), specimen surface electrical potential $(V)$ was mainly dropped by the Ti window $\left(\Delta V_{\mathrm{Ti}}\right)$ as well as $\mathrm{N}_{2}$ gas atmosphere $\left(\Delta V_{\mathrm{N} 2}\right)$.

$$
V=170 \mathrm{keV}-\Delta V_{\mathrm{Ti}}-\Delta V_{\mathrm{N} 2}
$$

$$
\begin{aligned}
\Delta V_{\mathrm{Ti}} & =T_{\mathrm{Ti}} / D_{\text {thTi }} \times 170 \mathrm{keV}=T_{\mathrm{Ti} \rho \mathrm{Ti}} /\left[66.7 \times(170 \mathrm{keV})^{2 / 3}\right] \\
& =\left(10^{-5} \mathrm{~m}\right) \times\left(4540 \mathrm{~kg} \mathrm{~m}^{-3}\right) /\left[66.7 \times(170 \mathrm{keV})^{2 / 3}\right] \\
& =22.2 \mathrm{keV}
\end{aligned}
$$$$
\Delta V_{\mathrm{N} 2}=T_{\mathrm{N} 2} / \mathrm{D}_{\text {thiN2 }} \times V_{\mathrm{Ti}}=T_{\mathrm{N} 2 \rho \mathrm{N} 2} /\left[66.7 \times\left(V_{\mathrm{Ti}}\right)^{2 / 3}\right]
$$$$
=\left(25 \times 10^{-3} \mathrm{~m}\right) \times\left(1.13 \mathrm{~kg} \mathrm{~m}^{-3}\right)
$$

$$
/\left[66.7 \times(170-22.2 \mathrm{keV})^{2 / 3}\right]=15.2 \mathrm{keV}
$$

Here, the specimen surface electrical potential, V, was estimated to be $129.6 \mathrm{keV}$ from the acceleration potential $\left(\mathrm{V}_{\mathrm{Acc}}=170 \mathrm{keV}\right)$, the $10 \mu \mathrm{m}$ thickness $(\mathrm{TTi})$ of the titanium window (density: $4540 \mathrm{~kg} \times \mathrm{m}^{-3}$ ), and the $25 \mathrm{~mm}$ distance between the sample and the window $\left(T_{\mathrm{N} 2}\right)$ in the $\mathrm{N}_{2}$ gas atmosphere (density: $\rho_{\mathrm{N} 2}=1.13 \mathrm{~kg} \mathrm{~m}^{-3}$ ). Since the dropped potential values were $22.2 \mathrm{keV}$ due to the Ti window and $15.2 \mathrm{keV}$ due to the $\mathrm{N}_{2}$ gas atmosphere respectively, the specimen surface electrical potential, $V$, is obtained to be $132.6 \mathrm{keV}$ using following calculation:

$$
\begin{aligned}
V & =170 \mathrm{keV}-22.2 \mathrm{keV}-15.2 \mathrm{keV} \\
& =132.6 \mathrm{keV}
\end{aligned}
$$

Based on the eq. (2) and density $\left(1760 \mathrm{~kg} \times \mathrm{m}^{-3}\right)$ of $\mathrm{CF}$, the penetration depth, $D_{\text {th }}$ of electron beam estimated was $123 \mu \mathrm{m}$. Since the CF's diameter was $6 \mu \mathrm{m}$ the electron beam is assumed to activate throughout the entire thickness deceasing dangling bond density. ${ }^{31,36)}$

\subsection{Bending test}

Bending tests were carried out at room temperature using a testing method for 3-point bending test (IMADA Co., Ltd. DPU-50N/MX-500N/GA-10N). ${ }^{1)}$ Here, distance between outside points on specimen, midpoint length, and head speed were $40 \mathrm{~mm}, 20 \mathrm{~mm}$, and $10 \mathrm{~mm} / \mathrm{min}$, respectively. To evaluate the fundamental mechanical property, bending stress-strain curves were obtained by using crosshead displacement and confirmed by using video recording device.

Evaluating the accumulative probability of strength $\left(P_{\mathrm{f}}\right)$ is a convenient method of quantitatively analyzing experimental values and in industry, is often employed in statistical quality control (QC). $P_{\mathrm{f}}$ is expressed by the following equation which is a generalized form of the median-rank method. ${ }^{37)}$

$$
P_{\mathrm{f}}=(i-0.3) /\left(N_{\mathrm{s}}+0.4\right)
$$

Here, $N_{\mathrm{s}}$ and $i$ are total number of samples and rank order integer of bending strength of each sample, respectively where $i$ is from weakest to strongest. In this case, $N_{\mathrm{s}}=11$ hence when $i$ values are 1, 5, and 11, their corresponding $P_{\mathrm{f}}$ values are $0.06,0.50$ and 0.94 , respectively.

\section{Results}

\subsection{Effects of EBI on bending properties}

Figure 2 illustrates bending strength $\left(\sigma_{\mathrm{b}}\right)$ against accumulative probability $\left(P_{\mathrm{f}}\right)$ of the $[\mathrm{PP}]_{4}[\mathrm{CF}]_{3}$ of $\mathrm{PP}$ reinforced by active $\mathrm{CF}$ irradiated under protective $\mathrm{N}_{2}$ gas atmosphere with $150 \pm 40 \mathrm{ppm}-\mathrm{O}_{2}$, together with untreated CF.

EBI dose of $0.22 \mathrm{MGy}$ under the $\mathrm{N}_{2}$ with $150 \pm 40 \mathrm{ppm}$ $\mathrm{O}_{2}$ slightly improves $\sigma_{\mathrm{b}}$ below 0.2 of low $P_{\mathrm{f}}$, as shown in Fig. 2. Since the most important practical $\sigma_{\mathrm{b}}$ for industrial application is the lowest value of $P_{\mathrm{f}}=0.06$, optimal $0.22 \mathrm{MGy}-\mathrm{EBI}$ dose under the $\mathrm{N}_{2}$ with $150 \pm 40 \mathrm{ppm}-\mathrm{O}_{2}$ atmosphere, which is confirmed in Fig. 2 showing at the low$P_{\mathrm{f}}=0.06$, is slightly larger than that of untreated. However, the caution is recommended since Fig. 2 shows higher doses greater than $0.30 \mathrm{MGy}$ degrade $\sigma_{\mathrm{b}}$ below that of untreated. The maximum $\sigma_{\mathrm{b}}$ value is found at $0.22 \mathrm{MGy}-\mathrm{EBI}$.

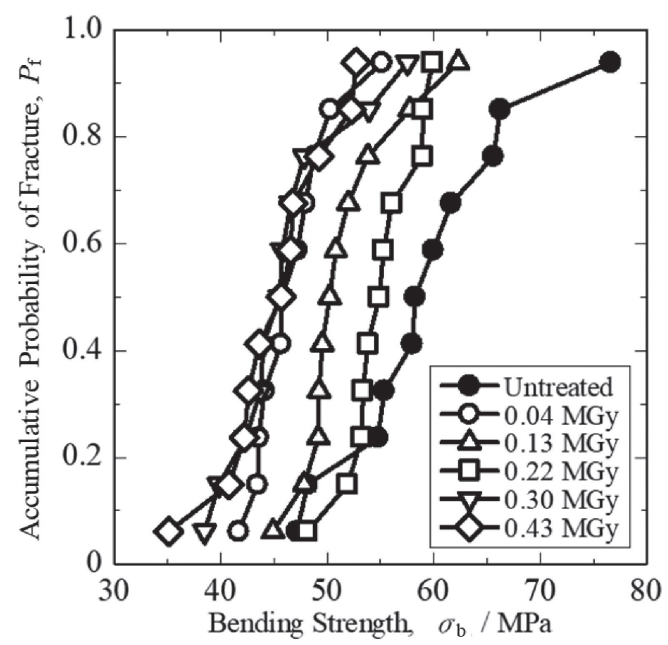

Fig. 2 Bending strength $\left(\sigma_{\mathrm{b}}\right)$ against accumulated probability $\left(P_{\mathrm{f}}\right)$ of PP reinforced by active $\mathrm{CF}$ irradiated under protective $\mathrm{N}_{2}$ gas atmosphere with $150 \pm 40$ ppm- $\mathrm{O}_{2}$, with untreated $\mathrm{CF}$. 


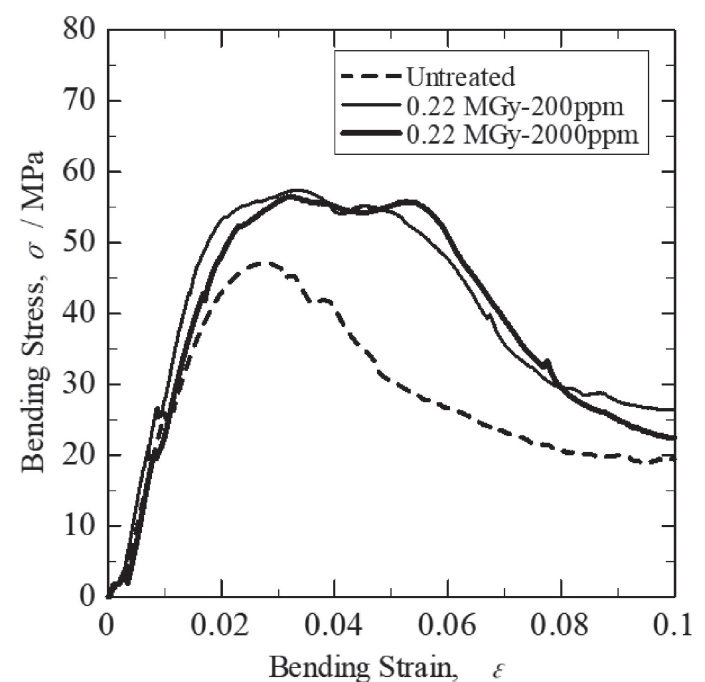

Fig. 3 Bending stress-strain curves at low accumulative probability $\left(P_{\mathrm{f}}\right)$ of 0.06 for the CFRTP samples at [0.22 MGy-EBI under protective $\mathrm{N}_{2}$ gas with $200 \mathrm{ppm}$ and 2,000 ppm- $\mathrm{O}_{2}$ ] conditions, respectively.

The $\sigma_{\mathrm{b}}$ difference from 0.94 to 0.06 of $P_{\mathrm{f}}\left(\Delta \sigma_{\mathrm{b}}\right)$ can be defined to be one of indicators of reliability. The $\Delta \sigma_{\mathrm{b}}$ values are $42,45,48,38$ and $35 \mathrm{MPa}$ for $0.04,0.13,0.22,0.30$ and $0.43 \mathrm{MGy}$, as well as $47 \mathrm{MPa}$ for untreated. The EBI decreases the $\Delta \sigma_{\mathrm{b}}$ and it does not improve the reliability. The optimal irradiation dose to get the highest reliability is obtained from $0.04 \mathrm{MGy}$ to $0.22 \mathrm{MGy}$.

\subsection{Bending test of CFRTP of PP dependence of oxygen content in protective oxygenated nitrogen gas atmosphere during EBI}

Figure 3 shows the bending stress-strain curves at low accumulative probability $\left(P_{\mathrm{f}}\right)$ of 0.06 for the CFRTP samples by applying optimal condition of $0.22 \mathrm{MGy}-\mathrm{EBI}$ under protective $\mathrm{N}_{2}$ gas each $200 \mathrm{ppm}$ and $2,000 \mathrm{ppm}-\mathrm{O}_{2}$ to the CF-CSM prior to assembly and hot press for the $[\mathrm{PP}]_{4}[\mathrm{CF}]_{3}$ samples. The maximum bending strength $\left(\sigma_{\mathrm{b}}\right)$ is improved about $21 \%$, to $57 \mathrm{MPa}$ over that of untreated $(47 \mathrm{MPa})$ at low accumulative probability $\left(P_{\mathrm{f}}=0.06\right)$. Moreover, bending elasticity $(\sigma / \varepsilon)_{\mathrm{b}}$ has slightly increased.

\subsection{Optical photographs of fractured samples}

Figure 4 shows the optical photographs of fractured samples $(\mathrm{Pf}=0.06)$ of the $\mathrm{PP}$ reinforced by $\mathrm{CF}$ untreated (see Fig. 4(a)) and treated by $0.22 \mathrm{MGy}-\mathrm{EBI}$ dose under nitrogen gas atmosphere with $2,000 \mathrm{ppm}$ oxygen concentration (see Fig. 4(b)). The photos show the treated sample in Fig. 4(b) has significantly less damage in the form of buckling, less ply separation in the form of peeling between the CF-CSMs and PP layers, and less fiber pullout than the untreated in Fig. 4(a).

\subsection{Effects of oxygen content in protective oxygenated nitrogen gas atmosphere during EBI on bending properties}

Figure 5 illustrates the maximum $\sigma_{\mathrm{b}}(\mathrm{a})$ and strain $\varepsilon_{\mathrm{b}}(\mathrm{b})$ at $\sigma_{\mathrm{b}}$ for the EBI 0.22 MGy under protective $\mathrm{N}_{2}$ gas atmosphere as a function of $\mathrm{O}_{2}$ concentration.

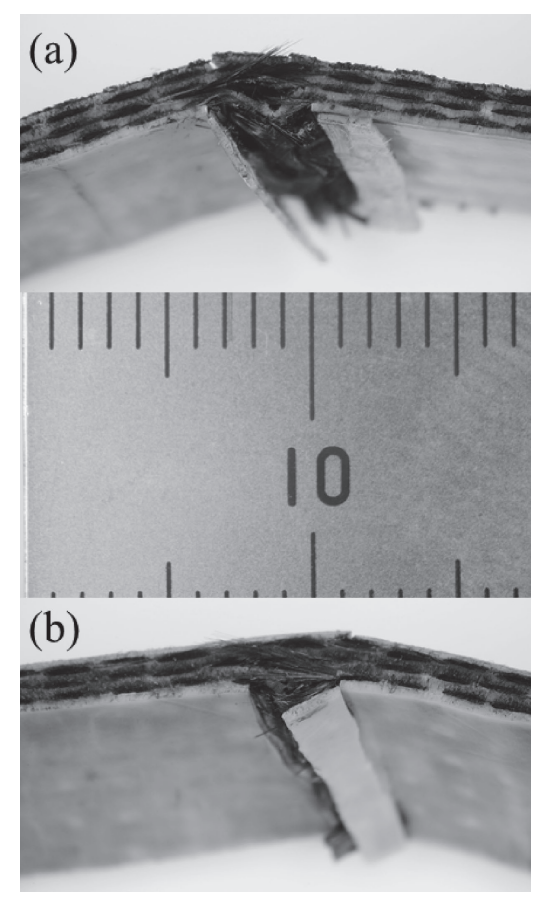

Fig. 4 Photographs fractured samples $\left(P_{\mathrm{f}}=0.06\right)$ of PP reinforced by $\mathrm{CF}$ untreated (a) and treated by $0.22 \mathrm{MGy}-\mathrm{EBI}$ dose under $2,000 \mathrm{ppm}-\mathrm{O}_{2}$ rich nitrogen gas atmosphere (b).

Figure 5(a) shows the $200 \mathrm{ppm} \mathrm{O}_{2}$ increased the $\sigma_{\mathrm{b}}$ at all $P_{\mathrm{f}}$ : from $76 \mathrm{MPa}$ to $80 \mathrm{MPa}$; $58 \mathrm{MPa}$ to $67 \mathrm{MPa}$; and $47 \mathrm{MPa}$ to $57 \mathrm{MPa}$ at high-, median-, and low- $P_{\mathrm{f}}$ of $0.94,0.50$ and 0.06, respectively. Moreover, Fig. 5(a) shows for the $0.22 \mathrm{MGy}-\mathrm{EBI}$ under $\mathrm{N}_{2}$ gas atmosphere with $\mathrm{O}_{2}$ concentrations from $200 \mathrm{ppm}$ to $2,000 \mathrm{ppm}$ increased the $\sigma_{\mathrm{b}}$ at all $P_{\mathrm{f}}$ less than or equal to medial 0.50 .

Figure 5(a) also shows that the $\sigma_{\mathrm{b}}$ difference from 0.94 to 0.06 of $P_{\mathrm{f}}\left(\Delta \sigma_{\mathrm{b}}\right)$, one of indicators of reliability are 23,11 , 18 and $40 \mathrm{MPa}$ for $0.22 \mathrm{MGy}$ under protective $\mathrm{N}_{2}$ gas atmosphere with $200 \mathrm{ppm}, 2,000 \mathrm{ppm}, 20,000 \mathrm{ppm}$ and $200,000 \mathrm{ppm}-\mathrm{O}_{2}$, as well as $30 \mathrm{MPa}$ for untreated and $12 \mathrm{MPa}$ for $0.22 \mathrm{MGy}$ EBI under $\mathrm{N}_{2}$ atmosphere with $150 \pm 40 \mathrm{ppm}-\mathrm{O}_{2}$ (see Fig. 2). The $0.22 \mathrm{MGy}-\mathrm{EBI}$ under $\mathrm{N}_{2}$ gas atmosphere with optimal $\mathrm{O}_{2}$ concentration from $150 \pm 40 \mathrm{ppm}$ to $20,000 \mathrm{ppm}$ apparently decreases the $\Delta \sigma_{\mathrm{b}}$ and improves the reliability.

On the other hand, Fig. 5(b) shows the $200 \mathrm{ppm} \mathrm{O}_{2}$ had apparent effect on the strain at $\sigma_{\mathrm{b}}\left(\varepsilon_{\mathrm{b}}\right)$ at more than $P_{\mathrm{f}}=0.6$, although the $\varepsilon_{\mathrm{b}}$ is reduced acting to make the more ductile thermoplastic more brittle.

Figure 6 shows changes in bending strength $\left(\sigma_{\mathrm{b}}\right)$ at the lowest accumulative probability $\left(P_{\mathrm{f}}=0.06\right)$ against $\mathrm{O}_{2-}$ concetration in protective $\mathrm{N}_{2}$ atmosphere during $0.22 \mathrm{MGy}-$ EBI of the weakest CFRTP samples of PP reinforced by 55 vol\%-CF with sizing film treated (Solid line).

The $0.22 \mathrm{MGy}-\mathrm{EBI}$ under $\mathrm{N}_{2}$ gas atmosphere with optimal $\mathrm{O}_{2}$ concentration from $150 \pm 40 \mathrm{ppm}$ to $200 \mathrm{ppm}$ apparently increases the bending strength $\left(\sigma_{\mathrm{b}}\right)$ from $48 \mathrm{MPa}$ to $57 \mathrm{MPa}$. Furthermore, the addition of $\mathrm{O}_{2}$ gas of more than $200 \mathrm{ppm}$ decreases the $\sigma_{\mathrm{b}}$ from $57 \mathrm{MPa}$ to $34 \mathrm{MPa}$. 
(a)

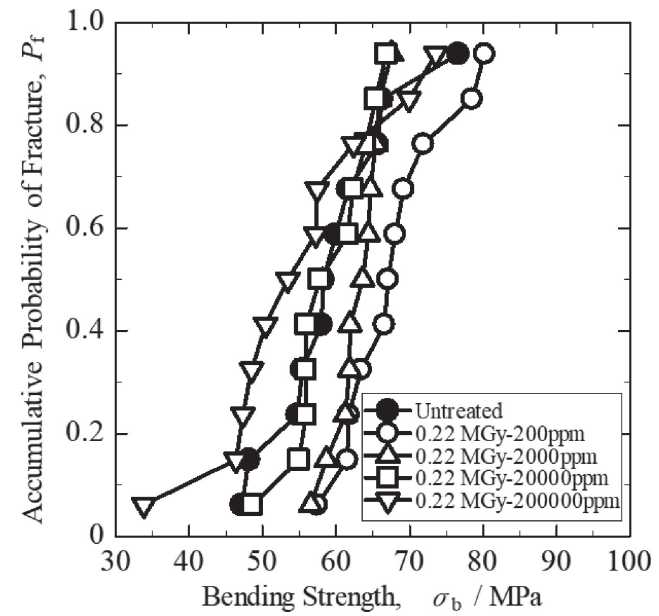

(b)

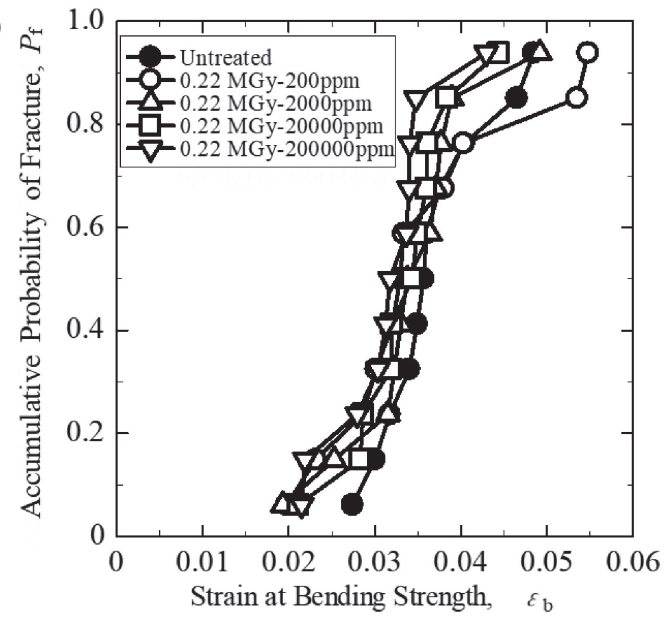

Fig. 5 Changes in bending strength $\left(\sigma_{\mathrm{b}}\right)$ against accumulative probability $\left(P_{\mathrm{f}}\right)(\mathrm{a})$ and its strain $\left(\varepsilon_{\mathrm{b}}\right)(\mathrm{b})$ for CFRTP of PP reinforced by $55 \mathrm{vol} \%$-CF untreated and treated at $0.22 \mathrm{MGy}-\mathrm{EBI}$ dose under the $\mathrm{O}_{2}$-rich $\mathrm{N}_{2}$ atmosphere.

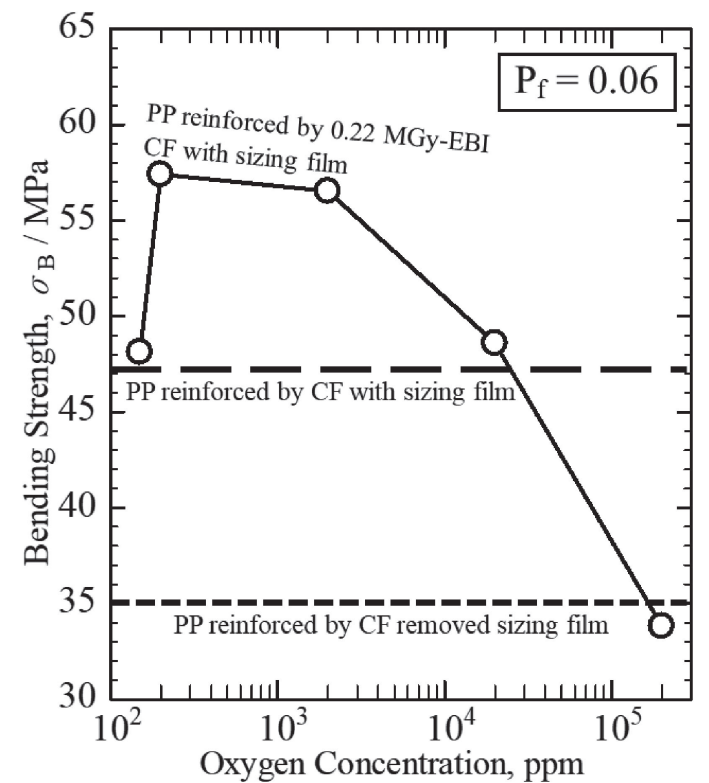

Fig. 6 Oxygen concentration dependent bending strength $\left(P_{\mathrm{f}}=0.06\right)$ of PP reinforced by $\mathrm{CF}$ treated with $0.22 \mathrm{MGy}-\mathrm{EBI}$ under protective $\mathrm{N}_{2}$ gas atmosphere with each $\mathrm{O}_{2}$ concentration (solid lines), together with $\mathrm{CF}$ untreated with (thick broken line) and without (thin broken line) sizing film.

\section{Discussion}

4.1 Effects of optimal $\mathrm{O}_{2}$ concentration in protective $\mathrm{N}_{2}$ atmosphere during EBI on bending strength induced by mutual entangling of sizing epoxy film on CF and PP matrix

Figure 6 also shows changes in bending strength $\left(\sigma_{\mathrm{b}}\right)$ at the lowest accumulative probability $\left(P_{\mathrm{f}}=0.06\right)$ of the weakest CFRTP samples of PP reinforced by 55 vol\%-CF with sizing film treated (solid line), together with untreated CF with and sizing film (thick broken and thin dotted lines), ${ }^{38)}$ respectively. The covering sizing film has improved the strength from $35 \mathrm{MPa}$ to $47 \mathrm{MPa}^{38)}$ The improvement of fracture strength of CFRTP untreated is probably caused by the mutual entangling between sizing epoxy film and PP.

As shown in Fig. 6, the 0.22 MGy-EBI under $\mathrm{N}_{2}$ gas atmosphere with optimal $\mathrm{O}_{2}$ concentration from $200 \mathrm{ppm}$ to $2,000 \mathrm{ppm}$ apparently increases the bending strength $\left(\sigma_{\mathrm{b}}\right)$. It is probably explained by mutual entangling of both sizing epoxy film on CF and PP with strong chemical bonding.

The covalent bonding formation of direct $\mathrm{CF}: \mathrm{C}: \mathrm{C}$ :PP induced by $\mathrm{EBI}$ and oxygen assists $\mathrm{CF}: \mathrm{C}: \mathrm{O}: \mathrm{C} ; \mathrm{PP}$ by concentrating the $\mathrm{O}_{2}$ gas molecules from $200 \mathrm{ppm}$ to 2,000 ppm- $\mathrm{O}_{2}$ in $\mathrm{N}_{2}$ atmosphere (see Fig. 1(b)), rather than in air, molecular bonding $\mathrm{CF}-\left(\mathrm{H}_{2} \mathrm{O}, \mathrm{N}_{2}, \mathrm{O}_{2}\right)$-PP for the untreated samples (see Fig. 1(a)). Polar oxygen groups created on the CF surface most likely contributed to bending strength enhancement. Therefore, converting from weak molecular bonds to the strong covalent bonds and broadening the contact area at carbon fiber/thermoplastic polypropylene interface leads to higher resistance to fiber pull-out with large friction force.

Furthermore, the addition of $\mathrm{O}_{2}$ gas from $20,000 \mathrm{ppm}$ to $200,000 \mathrm{ppm}$ tremendously decreases the $\sigma_{\mathrm{b}}(34 \mathrm{MPa})$, which is below the $\sigma_{\mathrm{b}}(35 \mathrm{MPa})$ of CFRTP of PP matrix reinforced by untreated $\mathrm{CF}$ without sizing film. It can be explained that the EBI absorbs impurity atoms and damages the covalent bonds of sizing epoxy film, as well as graphite hexagonal structure of CF. Thus, it is difficult to generate the mutual entangling. In addition, the excess $\mathrm{O}_{2}$ proliferates weak $\mathrm{F}: \mathrm{C}: \mathrm{O}: \mathrm{H}-\left(\mathrm{O}_{2}\right)-\mathrm{H}: \mathrm{O}: \mathrm{C}: \mathrm{PP}$ bonds (Fig. 1(a)), hence crowding the strong $\mathrm{CF}: \mathrm{C}: \mathrm{C}$ :PP and $\mathrm{CF}: \mathrm{C}: \mathrm{O}: \mathrm{C}$; PP bonds (Fig. 1(b)). Therefore, carefulness is highly recommended to adjust for optimum $\mathrm{O}_{2}$ concentration for practical applications.

Moreover, the action of the EBI apparently acts to clean residual $\mathrm{H}_{2} \mathrm{O}, \mathrm{N}_{2}$, and $\mathrm{O}_{2}$ to purify and activate the $\mathrm{CF}$ surface increasing polar group and active site density. The three processes probably work simultaneously that composition ratio can be controlled by $\mathrm{O}_{2}$ concentration.

With careful consideration to adjust for optimal conditions in fabricating parts, the $0.22 \mathrm{MGy}-\mathrm{EBI}$ in $\mathrm{O}_{2}$-rich $\mathrm{N}_{2}$ atmosphere appears to be a viable method to increase carbon fiber-thermoplastic polypropylene adhesion hence friction force to prevent fiber pull-out increasing the $\sigma_{\mathrm{b}}$ over the untreated enhancing reliability and safety of the PP-CFRTP.

\section{Conclusions}

To increase adhesion of carbon fiber to be difficult to adhere thermoplastic polypropylene, a new process of 
internal activation was achieved by applying electron beam irradiation in an $\mathrm{O}_{2}$-rich $\mathrm{N}_{2}$ atmosphere to interlayered carbon fiber chopped strand matts. This was prior to assembly with PP sheets, and one directional hot-press under 4.0 MPa at $473 \mathrm{~K}$ for $1 \mathrm{~min}$. Specimens were $3 \mathrm{CF}-\mathrm{CSMs}$ interlayered between $4 \mathrm{PP}$ sheets with layup $[\mathrm{PP}]_{4}[\mathrm{CF}]_{3}$.

(1) Results showed optimal condition of $0.22 \mathrm{MGy}-\mathrm{EBI}$ under $\mathrm{N}_{2}$ gas atmosphere with $200 \mathrm{ppm}$ to $2,000 \mathrm{ppm}$ $\mathrm{O}_{2}$ apparently increased the bending strength $\left(\sigma_{\mathrm{b}}\right)$ of the PP CFRTP (57 MPa), which was about $21 \%$ higher than that of untreated of $47 \mathrm{MPa}$ at low $P_{\mathrm{f}}$ of 0.06 .

(2) It was probably explained by mutual entangling of both sizing epoxy film on $\mathrm{CF}$ and $\mathrm{PP}$ with strong covalent bonding formation of direct $\mathrm{CF}: \mathrm{C}: \mathrm{C}: \mathrm{PP}$ induced by $\mathrm{EBI}$ and oxygen assisted $\mathrm{CF}: \mathrm{C}: \mathrm{O}: \mathrm{C} ; \mathrm{PP}$ by concentrating the $\mathrm{O}_{2}$ gas molecules from $200 \mathrm{ppm}$ to $2,000 \mathrm{ppm}-\mathrm{O}_{2}$ in $\mathrm{N}_{2}$ atmosphere, rather than in air, molecular bonding $\mathrm{CF}-\left(\mathrm{H}_{2} \mathrm{O}, \mathrm{N}_{2}, \mathrm{O}_{2}\right)$-PP for the untreated samples. Polar oxygen groups created on the CF surface most likely contributed to bending strength enhancement.

(3) In addition, the action of the EBI apparently acts to clean residual $\mathrm{H}_{2} \mathrm{O}, \mathrm{N}_{2}$, and $\mathrm{O}_{2}$ to purify and activate the CF surface increasing polar group and active site density. They most likely contributed to bending strength enhancement.

(4) The 0.22 MGy-EBI in $\mathrm{O}_{2}$-rich $\mathrm{N}_{2}$ atmosphere appears to be a viable method to increase carbon fiber-thermoplastic polypropylene adhesion enhancing reliability and safety of the PP-CFRTP.

(5) Furthermore, the addition of $\mathrm{O}_{2}$ gas of $20,000 \mathrm{ppm}$ to $200,000 \mathrm{ppm}$ apparently decreased the $\sigma_{\mathrm{b}}$. It is below the $\sigma_{\mathrm{b}}(35 \mathrm{MPa})$ of CFRTP of PP matrix reinforced by untreated $\mathrm{CF}$ without sizing film. It can be explained that the EBI absorbs impurity atoms and damages the covalent bonds of sizing epoxy film, as well as graphite hexagonal structure of CF. Thus, it is difficult to generate the mutual entangling.

\section{Acknowledgements}

The authors wish to thank Mr. Yasuo Miyamoto (ESR), Ryo Nomura, Anna Takahashi, Naruya Tsuyuki, Daisuke Kitahara, Sagiri Takase, and Prof. Yoshihito Matsumura of Tokai University for their useful help. Our sincere gratitude also goes to Eye Electron Beam Co, Ltd. (Ghoda, Saitama, Japan) for their support with this work. This work was partly supported by the JSPS Core-to-Core Program and A. Advanced Research Networks, "International research core on smart layered materials and structures for energy saving".

\section{REFERENCES}

1) H. Hasegawa, M.C. Faudee, Y. Enomoto, S. Takase, H. Kimura, A. Tonegawa, Y. Matsumura, I. Jimbo, M. Salvia and Y. Nishi: Mater. Trans. 58 (2017) 1606-1615.

2) M. Sharma, S. Gao, E. Mader, H. Sharma, L.-Y. Wei and J. Bijwe:
Compos. Sci. Technol. 102 (2014) 35-50.

3) M. Sharma, S. Gao, E. Mader, H. Sharma, L.-Y. Wei and J. Bijwe: Compos. Sci. Technol. 102 (2014) 35-50.

4) M.C. Paiva, C.A. Bernardo and M. Nardin: Carbon 38 (2000) 13231337.

5) H. Dvir, J. Jopp and M. Gottlieb: J. Colloid Interface Sci. 304 (2006) 58-66.

6) S.J. Park and B.J. Kim: Mater. Sci. Eng. A 408 (2005) 269-273.

7) S. Tiwari and J. Bijwe: Procedia Tech 14 (2014) 505-512.

8) Z. Xu, L. Chen, Y. Huang, J. Li, X. Wu, X. Li and Y. Jio: Eur. Polym. J. 44 (2008) 494-503.

9) Z. Wu, C.U. Pittman, Jr. and S.D. Gardner: Carbon 33 (1995) 597605.

10) S. Tiwari, M. Sharma, S. Panier, B. Mutel, P. Mitschang and J. Bijwe: J. Mater. Sci. 46 (2011) 964-974.

11) C.U. Pittman, W. Jiang, G.R. He and S.D. Gardner: Carbon 36 (1998) 25-37.

12) M.A. Sherwood: Electron Spectrosc. Relat. Phenom. 81 (1996) 319342 .

13) M.A. Montes-Morán, A. Martínez-Alonso, J.M.D. Tascón and R.J. Young: Compos., Part A 32 (2001) 361-371.

14) B. Hung, J. Li, Q. Fan and Z.H. Chen: Compos., Part A 39 (2008) 1133-1140.

15) D. Bao and X. Cheng: J. Rare Earths 24 (2006) 564-568.

16) X.R. Zhang, P. Zhao, X.Q. Pei, Q.H. Wang and Q. Jia: Express Polym. Lett. 1 (2007) 667-672.

17) R.L. Clough: Nucl. Instrum. Methods Phys. Res., Sect. B 185 (2001) 8-33.

18) Z. Xu, Y. Huang, C. Zhang, L. Liu, Y. Zhang and L. Wang: Compos. Sci. Technol. 67 (2007) 3261-3270.

19) Y.Z. Wan, Y.L. Wang, Y. Huang, H.L. Luo, G.C. Chen and C.D. Yuan: J. Mater. Sci. 40 (2005) 3355-3359.

20) J. Li, Y. Huang, Z. Xu and Z. Wang: Mater. Chem. Phys. 94 (2005) 315-321.

21) A. Mizutani and Y. Nishi: Mater. Trans. 44 (2003) 1857-1860.

22) Y. Nishi, S. Ishii, S. Inui, A. Kasai and M.C. Faudree: Mater. Trans. 55 (2014) 323-326.

23) H. Hasegawa, M.C. Faudree, Y. Matsumuara, I. Jimbo and Y. Nishi: Mater. Trans. 57 (2016) 1202-1208.

24) R. Nomura, M. Kanda, M.C. Faudree, I. Jimbo and Y. Nishi: Mater. Trans. 57 (2016) 417-422.

25) K. Oguri, K. Fujita, M. Takahashi, Y. Omori, A. Tonegawa, N. Honda, M. Ochi, K. Takayama and Y. Nishi: J. Mater. Res. 13 (1998) 33683371.

26) K. Oguri, N. Iwataka, A. Tonegawa, Y. Hirose, K. Takayama and Y. Nishi: J. Mater. Res. 16 (2001) 553-557.

27) K. Oguri and Y. Nishi: Mater. Trans. 45 (2004) 1346-1349.

28) Y. Nishi, S. Iizuka, M.C. Faudree and R. Ohyama: Mater. Trans. 53 (2012) 940-945.

29) A. Kasashima, N. Iwataka, J. Kawano, N. Honda and Y. Nishi: J. Adv. Sci. 9 (1997) 70-71.

30) Y. Nishi, T. Toriyama, K. Oguri, A. Tonegawa and K. Takayama: J. Mater. Res. 16 (2001) 1632-1635.

31) Y. Nishi, A. Mizutani, A. Kimura, T. Toriyama, K. Oguri and A. Tonegawa: J. Mater. Sci. 38 (2003) 89-92.

32) Y. Nishi, A. Mizutani and N. Uchida: J. Thermoplastic Compos. Mater. 17 (2004) 289-302.

33) K. Iwata and Y. Nishi: Mater. Trans. 49 (2008) 2058-2062.

34) A. Mizutani and Y. Nishi: Mater. Trans. 44 (2003) 1857-1860.

35) R. Christenhusz and L. Reimer: Z. Angew. Phys. 23 (1967) 396-404.

36) Y. Nishi, T. Toriyama, K. Oguri, A. Tonegawa and K. Takayama: J. Mater. Res. 16 (2001) 1632-1635.

37) S.J. Park and B.J. Kim: Mater. Sci. Eng. A 408 (2005) 269-273.

38) S. Kitagawa, H. Kimura, S. Takase, N. Tsuyuki, D. Kitahara, A. Takahashi, M.C. Faudree, H.T. Uchida, A. Tonegawa, M. Kanda, N. Inoue, S. Kaneko, T. Endo, M. Salvia and Y. Nishi: Trans. Mater. Res. Soc. Jpn. 43 (2018) 125-128. 